\title{
Applying a Yin-Yang Perspective to the Theory of Paradox: A Review of Chinese Management
}

\author{
Guoli Liu' \\ $\operatorname{Ran} \mathrm{An}^{2}$ \\ 'School of Business Administration, \\ South China University of Technology, \\ Guangzhou, China and Guangxi \\ University, Nanning, People's Republic of \\ China; ${ }^{2}$ School of Business \\ Administration/School of Communication \\ and Journalism, South China University of \\ Technology, Guangzhou, People's \\ Republic of China
}

\begin{abstract}
This paper examines the paradox in management through the yin-yang lens and how to apply the yin-yang perspective in Chinese indigenous management research through a literature review. Compared with several western philosophical perspectives, yin-yang places more emphasis on the interaction of interdependent contradictions and better describes the complex dynamics of both contradictions. Our review finds that the scholars propose yinyang as a supplement to and an optimization of western management. The review focuses on connecting the yin-yang perspective with the paradox in management, cross-cultural management, and practice of organizational management.
\end{abstract}

Keywords: paradox, yin-yang, Chinese management science, organizational management, review

\section{Introduction}

Western modern management theory has influenced the formation of mainstream Chinese management science after it was introduced to China. However, many scholars have found that directly applying western management systems does not fit Chinese enterprises and organizations well. ${ }^{1-5}$ For example, western scholars have introduced cooperative governance thinking and discussed building a cooperative relationship between government and non-profit organizations in public service. However, in view of the unique characteristics of China's non-profits, there is a lack of research on the dynamic changes in the opposition and unity between the Chinese government and non-profits. In addition, in cross-cultural organizations in China, the relationship of confrontation and coordination between China and foreign nations is constantly emerging in organizational issues, and the division of power and responsibility is often in dispute. ${ }^{6,7}$ An important reason for this is the contradiction and divergence between western management philosophy and traditional Chinese philosophy. ${ }^{8-10}$ Therefore, more detailed and indigenous research, theory, and work are required, rather than the simplistic reproduction of western models based on "assumptions, perspectives and biases that are simply just not applicable or appropriate in China". ${ }^{11}$

To fully explain some behaviours and performances of Chinese indigenous organizations, the use of Chinese traditional philosophical thinking is required to modify, supplement, enrich, or even replace traditional western concepts or theories in some cases. ${ }^{1}$ China's indigenous organizational management research needs to adopt the perspective of localization, use local management philosophy and thought, and integrate it with western culture and management thought so as to adopt its strengths and compensate for its weaknesses. ${ }^{12,13}$ 
With contradictions in demands emerging in organizational management, an increasing number of western scholars have analysed the organizational environment of globalization, and dynamic and diversified competition from the perspective of paradox in management. ${ }^{14}$ The western paradox in management is similar to, but very different from, the Chinese traditional yin-yang. ${ }^{15-18}$ By contrast, eastern philosophies stress the need to avoid simplistic distinctions. ${ }^{15}$ Thus, we propose a paradox in management through the yin-yang lens and reveal how to apply the yin-yang perspective to Chinese indigenous management research through a literature review. Can yin-yang philosophy provide a new conceptual frame of reference or perspective to supplement the western management system as well as theoretical support for the indigenous research of organizational management, and, if it does, how?

\section{Paradox in Management}

Paradox has many conceptual meanings in western academic circles, which are commonly used in the fields of traditional philosophy and psychology. ${ }^{15}$ In traditional western philosophy, philosophers regard human existence as paradoxes, such as life and death, and good and bad. Aristotle, Hegel, and other traditional philosophers described paradox as irrational and unsolvable problems or double constraints. ${ }^{19}$ Psychologists have emphasized the cognitive nature of paradox to study its impact on creativity and mental health. ${ }^{15}$

With more conflicting demands, opposing perspectives, or seemingly illogical findings emerging in western organization management, an increasing number of western scholars have analysed the global, dynamic, and competitive organizational environments from the perspective of paradox in management. ${ }^{20}$

Ford and Backoff define paradox in management as "some "thing" that is constructed by individuals when oppositional tendencies are brought into recognizable proximity through reflection or interaction". When trying to understand the ambiguous and dynamic world, reality is often simplified as a polarization of either/or, which hides complex mutual relations. ${ }^{20} \mathrm{~A}$ paradox can express all kinds of contradictory but interwoven elements. March ${ }^{21}$ believes that organizations need to balance innovation and existing capabilities effectively. If the organization does not innovate, there will be no competition prospect, yet excessive innovation will reduce profits. Only by finding a balance between the two can an organization be stable and efficient. ${ }^{21}$ Similarly, Lewis believes that the root of paradox lies in the simultaneity of the two poles, though the cognitive nature of the two poles often conceals the coexistence of conflicts. In contrast to either/or choices, paradoxical tensions signify two sides of the same coin, which is a whole that exists at the same time. ${ }^{15}$ When western management scholars analyse the paradox in management, they tend to reveal the differences and opposites of the dominant bipolar nature or manifestation of contradiction.

\section{Yin-Yang: A Chinese Perspective}

Yin-yang is a Chinese philosophy and lifestyle that embraces paradox, dynamics, and change. ${ }^{22}$ It involves three tenets: dialectical, holistic, and dynamic. In Chinese philosophy, the union of yin and yang is a state of equilibrium. ${ }^{23}$ The yin-yang model captures the idea that there are no opposites - there is no absolute borderline between black (yin) and white (yang); a dot of yin exists in yang, and a dot of yang also exists in yin. ${ }^{9}$ Displaying the dynamic interaction between two opposite sides, the yin-yang model (Figure 1) embraces the coexistence of opposite elements in the same environment. ${ }^{4}$ Yin and yang form a dialectical balance that reflects the natural and organic core of existence, in which forces are complementary. ${ }^{3}$ In the yin-yang model, yin represents feminine forces, such as the moon, water, darkness, passivity, intuition, softness, contraction, and yielding in the

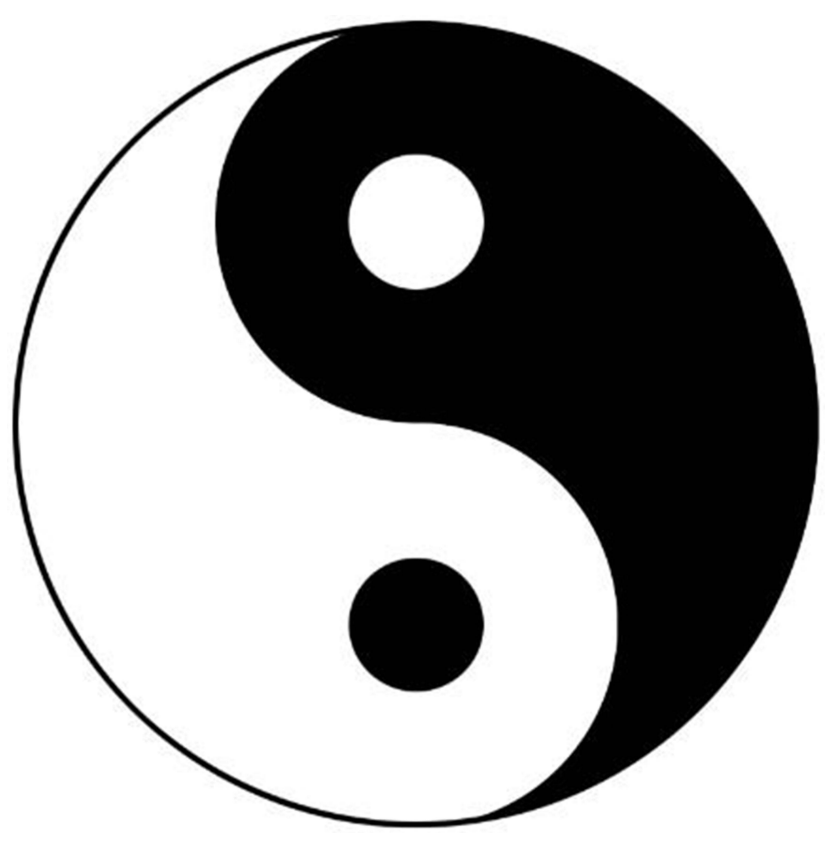

Figure I Model of yin-yang. 
universe, while yang represents masculine forces, such as the sun, fire, light, activity, rational thought, hardness, expansion, and assertiveness. ${ }^{24}$ Thus, although the $\mathrm{S}$ line divides the circle into two sides, the dark and white areas are interdependent and interpenetrative. ${ }^{25}$ The small eye in the white and dark areas demonstrates the interwoven and dynamic nature of the yin and yang forces, respectively. ${ }^{25}$

Scholars in the field of traditional Chinese medicine often interpret yin-yang as a philosophical theory. However, strictly speaking, yin-yang is not a speculative philosophy of western rationalism. In this study, the concept of yin-yang does not constitute a theory in academic research - there is no formulation of yin-yang theory. In modern academic research, yin and yang are essentially a concept and mode of thinking, so scholars like to call it yin-yang thinking or frame ${ }^{3-5}$ or yin-yang perspective. ${ }^{9,24}$ Based on this, yin-yang thinking is defined as a dynamic, dialectical, comprehensive, holistic, and harmonious way of thinking. ${ }^{22,23}$ It has three main characteristics. First, it emphasizes the relationship of opposition and complementarity, that is, yin and yang may be two sides of a contradiction but the two aspects of contradiction or opposition are not absolute; rather, they are interrelated, and they feel and push each other. ${ }^{19}$ Second, competition exists in rival forces. ${ }^{23}$ The opposite movement of yinyang is mutual dependence, which needs to see the alternate development of the two sides from the perspective of change and development. The third is the pursuit of harmony and balance. As a whole, the universe is antagonistic to yin-yang, which leads to conflicts. However, the ultimate ideal state is the great harmony between the two sides of the contradiction, ${ }^{22}$ forming a stable and sustainable development. The yin-yang perspective is the thinking and analysis of dynamic duality based on yin-yang thinking. It emphasizes that all things are each composed of one yin and one yang, which are not only contradictory but also complementary. The yin-yang perspective seems the best choice to coordinate and integrate the opposing views to regard all disputes or differences as two sides of yin-yang, so as to avoid prejudice in any aspect. ${ }^{3}$

In recent years, the wellspring of Chinese philosophical thoughts, the yin-yang philosophy has been widely discussed in Chinese and international academics, particularly those related to medical science, information science, social science disciplines and cross-disciplinary studies. For example, Langevin et $a^{26}$ develop and evaluate a method for quantitative evaluation of yin and yang scores in human subjects for the purposes of traditional
Chinese medicine research; Zhang and Zhang ${ }^{27}$ propose bipolar fuzzy sets in the field of information science to reveal a yin-yang fusion of two interactive fuzzy subsystems. This paper mainly focuses on the related aspects of yin-yang in the field of management, and tries to explore the essential relationship between paradox in management and yin-yang from the philosophical root.

\section{Paradox and Yin-Yang}

There have been some scholars comparing the western paradox framework and Chinese yin-yang to some extent (eg, Chin et al. ${ }^{28} \mathrm{Li}$ et al. ${ }^{29}$ Redding $;{ }^{30} \mathrm{Li} ;{ }^{17}$ Luo and Zheng ${ }^{31}$ ). However, we try to systematically put forward the common characteristics and essential differences between paradox and yin-yang. The concept of the binary paradox is similar to the "unity of opposites" emphasized by yin-yang thinking in traditional Chinese philosophy. However, unlike yin-yang, the paradox in management lacks the dynamic characteristics of "competition in rival forces" and "mutual transformation". Figure 2 is a comparison of several western philosophical perspectives and yin-yang thinking in the study of paradox in management.

In the study of paradox in management, discussions on some western traditional philosophical perspective are similar to those on the yin-yang perspective, but there are also some essential differences. From Aristotle's logical point of view, the two sides of the contradiction are completely independent, without development and movement. This is an isolated and static either/or way of thinking. ${ }^{3}$

Hegel criticized Aristotle's metaphysics and put forward the dialectics of internal contradiction, which states that everything is self-contradictory. ${ }^{32}$ The use of Hegel's dialectics to study paradox in management emphasizes the unity of opposites, which is the logical thinking of both/ and. This is consistent with the basic characteristics of opposition and unity of yin-yang thinking. However, Hegel put forward the concept of aufheben of the two opposite sides, believing that the contradiction between new and old contradictions is the inevitable law of the development of things, in which process contradictions will eventually be eliminated; ${ }^{32}$ this is different from the transformation of yin-yang thinking for two opposite sides. From the perspective of yin-yang, there may be two situations in which the two opposite sides are "competition in rival forces", similar to Hegel' s aufheben. When the contradiction between the two opposite sides 


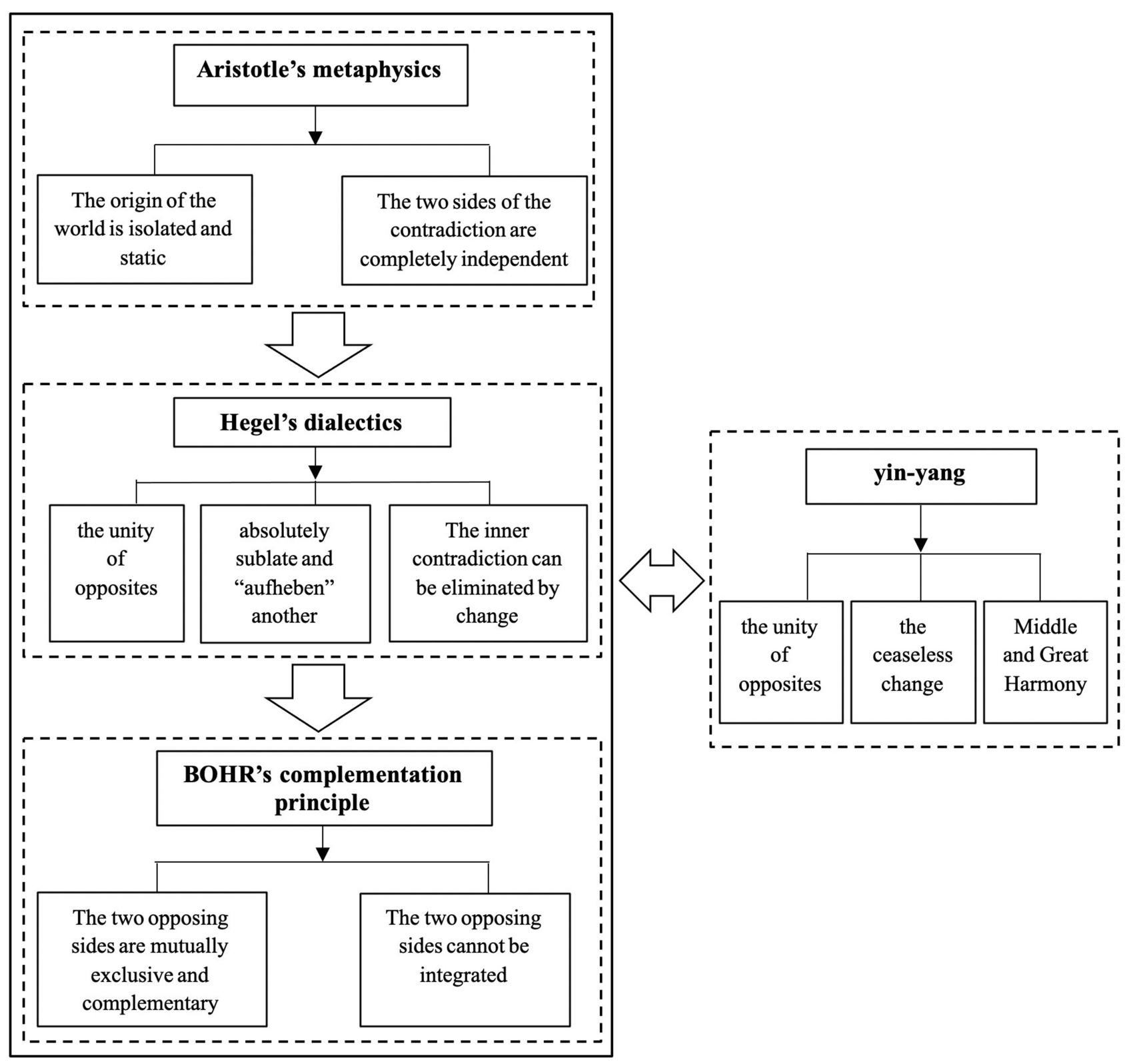

Figure 2 Western philosophical perspectives and yin-yang in the study of management paradox.

intensifies to a certain extent, there will be a revolutionary change in which one side attempts to eliminate the other side, ${ }^{22}$ that is, "Qi hui nai wang" mentioned in the book of I-Ching. Second, while the two opposite sides were more through negotiation in the process of "competition in rival forces" in the struggle, not all but a part of them was transformed, resulting in "yang flourishing and yin declining" or "yin flourishing and yang declining", thus moving towards the harmonious ideal state of "middle" and "great harmony". 33

Bohr ${ }^{34}$ proposed the application of the "complementarity principle" to explain quantum mechanics and used the yin- yang diagram to express the characteristics of the complementary principle. His complementary principle is similar to yin-yang thinking, which is that the opposite sides repel and complement each other. Both emphasize the opposition and unity of contradiction, and think that the two sides are contrasting and complementary. However, similar to the logic of most western dualism, the principle of complementarity is still based on either/or in epistemology, emphasizing that the opposite poles are exclusive and cannot be integrated. ${ }^{34}$ This is different from the idea that the opposite sides of yin-yang thinking emphasize mutual penetration and can form a harmonious and unified whole. ${ }^{17}$ 
Generally speaking, western dialectics, represented by Aristotle and Hegel, is a contradictory dialectics focusing on the dichotomy of matter and self and the development of rational logic. Chinese traditional dialectics, represented by Lao Tzu, Confucius and the book of I Ching, is a harmonious dialectics focusing on the unity of man and nature and the development of perceptual intuition. The main difference between the two is that the contradictory dialectics emphasizes the binary opposition of phenomenon and essence, subject and object, material and spirit, with logic as the core; the harmonious dialectics emphasizes the life movement process of human and nature and the harmonious process of opposition and mutual transformation of yin-yang, with perception as the basic. Traditional Chinese philosophy places more emphasis on the interaction of interdependent contradictions. $^{23}$ In the first sentence of Tao Te Ching, Lao Tzu mentioned that "Tao that can be spoken of is not the true one". It seems that the inexplicable eternal Tao referred to here is consistent with the "irrational complex ambiguity" mentioned in the western paradox. ${ }^{15}$ But "Dao begets one, one is two, two is three, and three is all things" in yin-yang philosophy further interprets the dynamic interoperability of both sides of the contradiction, which is usually displayed as either/or in the western paradox in management. Traditional Chinese philosophy with yin-yang thinking as the main research perspective can better describe the complex and changeable duality as well as the complex dynamics of both contradictions than the western paradox theory. ${ }^{15}$ In organizational management, the key is how to effectively deal with these paradoxes and unify these paradoxes and contradictions in the balance of dynamic development. This dynamic balance implies "the unity of opposites", "the ceaseless change of production and reproduction", or "middle" and "great harmony" in yin-yang philosophy. In summary, the literature review finds that yin-yang provides a new perspective and a more appropriate indigenous method for the western paradox.

\section{Yin-Yang Perspective in Organizational Management}

As a classical traditional Chinese philosophy, yin-yang thinking or perspective has been actively explored and applied to research and practice by contemporary scholars. However, the application of yin-yang in the field of management is still in the exploratory stage. The introduction of the Western modern management theory has gradually helped form the mainstream Chinese management system. However, there are contradictions and differences between traditional Chinese philosophy and western management philosophy. Applying the western management system directly may not fit Chinese organizations well. ${ }^{1}$ Therefore, to fully explain some Chinese organizations' behaviour, we should use the yin-yang perspective to modify, supplement, enrich, or even replace western traditional concepts or theories. The yin-yang perspective can be used as a macro research paradigm in the east to supplement or replace the western either/or logic., ${ }^{3,9}$ Therefore, applying the yin-yang perspective is more in line with the characteristics of Chinese indigenous research. Yin-yang is very important for improving the western one-sided, static, linear either/or logic and the absolute binary separation theory. ${ }^{3-5}$

As yin-yang is especially useful for theorizing in Chinese organizations, an increasing number of Chinese scholars have used this philosophy in research (see Table 1). On the one hand, domestic scholars in interdisciplinary fields such as management and philosophy try to use traditional Chinese philosophy to adjust and correct the "acclimatization" of western management theory system to Chinese enterprises. ${ }^{5,18}$ On the other hand, many overseas Chinese scholars believe that traditional oriental philosophy, especially the yin-yang perspective, is particularly suitable for Chinese transnational organizations. ${ }^{35,36} \mathrm{Li}^{3}$ proposed that yin-yang thinking can regard the opposition between globalization and localization as a dynamic dualism to avoid any possible onesided bias. $\mathrm{Li}^{17}$ proposes a duality map tool of yin-yang and believes that dynamic dialectical yin-yang thinking is more suitable for paradox management than the static dialectical logic of either/or and both/and. In the binary diagram of organizational paradox management, the relationship between social value and organizational profit, exploration and utilization, competition, and cooperation can provide better solutions from the perspective of the balance of yin-yang. ${ }^{17}$

\section{Connecting the Paradox in Management and Yin-Yang}

In studying the paradox in management, western scholars found that the dichotomy of traditional western philosophy is too simple and directly shows the management paradox as a conflict between two poles, when the use of Chinese 
Table I Organizational Management Literature from Yin-Yang Perspective: A Summary

\begin{tabular}{|c|c|c|}
\hline Characteristics & Main Literature & Main Points \\
\hline $\begin{array}{l}\text { Emphasizing the importance of Chinese } \\
\text { traditional yin-yang thinking for the study of } \\
\text { local management system }\end{array}$ & Li 20I0, 20I2, 20I4; Xie and Wei 2012 & $\begin{array}{l}\text { - The relative balance of yin-yang is different } \\
\text { from and better than Hegel's absolute } \\
\text { sublation of dialectics. } \\
\text { - Yin-yang thinking is similar to Bohr's } \\
\text { complementary principle. } \\
\text { - Yin-yang thinking is more in line with the } \\
\text { characteristics of indigenous Chinese } \\
\text { management research. }\end{array}$ \\
\hline $\begin{array}{l}\text { Supplementing with and optimizing yin-yang } \\
\text { to western management system, the collision } \\
\text { and integration of Chinese and western } \\
\text { management theories }\end{array}$ & $\begin{array}{l}\text { Cheng 1992, 20I0, 20I7; Fang 2005, 20I2; Lu } \\
\text { et al 20I3; Li and Yang 20I7 }\end{array}$ & $\begin{array}{l}\text { - It should not only contain the spirit of } \\
\text { western scientific management but also absorb } \\
\text { the wisdom of Chinese philosophical } \\
\text { management. } \\
\text { - Yin-yang perspective can supplement the } \\
\text { deficiency of western management theory } \\
\text { from dynamic and dialectical aspects. } \\
\text { - Yin-yang thinking needs to be integrated with } \\
\text { western culture and management thought. }\end{array}$ \\
\hline $\begin{array}{l}\text { Connecting the paradox in management and } \\
\text { yin-yang }\end{array}$ & $\begin{array}{l}\text { Lewis 2000; Smith and Lewis 20II; Li 20I6; } \\
\text { Smith et al 20I7; Su } 2017\end{array}$ & $\begin{array}{l}\text { - The binary paradox in organizational } \\
\text { management is similar to the yin-yang thinking. } \\
\text { - Yin-yang perspective is better than the } \\
\text { paradox of western management to describe } \\
\text { the complex dynamics of both sides of the } \\
\text { contradiction. } \\
\text { - Yin-yang provides a new perspective and an } \\
\text { appropriate way to solve the paradox. }\end{array}$ \\
\hline $\begin{array}{l}\text { Involving yin-yang perspective in the cultural } \\
\text { research of organizational management and } \\
\text { cross-cultural management }\end{array}$ & $\begin{array}{l}\text { Fang 2005, 2012; Faure and Fang 2008; Chen } \\
\text { 2008, 2016; An et al 2018; Chen 2018; } \\
\text { Pauluzzo et al } 2018\end{array}$ & $\begin{array}{l}\text { - There is a whole, dynamic, and dialectical } \\
\text { paradoxical value in any culture. } \\
\text { - The dialectical interaction between yin and } \\
\text { yang is the basis of the formation of human } \\
\text { communication theory } \\
\text { - Contemporary Chinese culture has } \\
\text { undergone great changes, but the traditional } \\
\text { thinking of yin-yang still runs through modern } \\
\text { Chinese society. }\end{array}$ \\
\hline $\begin{array}{l}\text { Emphasizing that yin-yang should be included } \\
\text { in management theory, and should guide the } \\
\text { practice of organizational management }\end{array}$ & $\begin{array}{l}\text { Li et al 20II; Du et al 20II; Lu et al 20I3; Jing } \\
\text { and Van de Ven. 20I4; Horak and Long 20I8; } \\
\text { Lin et al 20I8; Lee and Reade 20I8; Chin et al } \\
2020\end{array}$ & $\begin{array}{l}\text { - In China's local management practice, the } \\
\text { enterprises using yin-yang thinking will form } \\
\text { a "humanized" management paradigm that } \\
\text { combines rules with humanity. } \\
\text { - The concept of change plays an important } \\
\text { role in guiding organizational change in Chinese } \\
\text { local enterprises. } \\
\text { - Yin-yang is used to guide the balance and } \\
\text { integration of individualism and collectivism in } \\
\text { cross-cultural management. } \\
\text { - As a local study of management, the idea is } \\
\text { not just to explore the philosophy of yin-yang } \\
\text { but to develop new knowledge of management } \\
\text { from the perspective of yin-yang philosophy. }\end{array}$ \\
\hline
\end{tabular}


yin-yang thinking or perspective can better explain and analyse its complexity and dynamic multilateralism at a deeper level. ${ }^{15} \mathrm{Li}^{7}$ believes that compared with Hegel's dialectics, the differences in yin-yang thinking lie in integrity, conditional mutual transformation, and the permanence of contradictions. In traditional western philosophy, Aristotle's either/or and Hegel's both/and are often used as the core of dualistic logic, while the dualistic framework of traditional Chinese philosophy takes either/ and of the balance of yin-yang as the core of logic, emphasizing the interaction and harmonious unity of the two opposites. However, by criticizing Perter P. Li's either/ and logic, ${ }^{3} \mathrm{Li}^{37}$ believed the both/and logic is an indispensable element of yin-yang, which cannot adequately describe the diversity of epistemological expressions and methodological prescriptions derived from yin-yang thinking. Li believed the structure of Hegel's dialectical sublation in paradox is almost same as that of the change process of yin-yang. ${ }^{37}$ Although the essence of yin-yang is similar to the paradox in the west, ${ }^{30,38}$ there are significant differences in determining priorities and implementing decisions in the field of strategic management. ${ }^{30}$ Cheng ${ }^{1}$ put forward the $\mathrm{C}$ theory, pointing out that many western scholars only emphasized the overall culture and style of Chinese management system and psychological characteristics but did not explore the deep ideological and philosophical basis of Chinese management system and style. C stands for "creativity, change, culture, Chinese tradition and Confucianism and their creative". ${ }^{2}$ Cheng ${ }^{1}$ integrates humanized management and rational management to form the $\mathrm{C}$ principle to guide the practical development and implementation of Chinese management.

\section{Cultural Research of Organizational Management and Cross-Cultural Management Based on the Yin-Yang Perspective}

In cross-cultural management and cultural research of organizational management, some scholars use the yinyang perspective to highlight the dynamic, complementary, and holistic perspectives. Fang ${ }^{8}$ was the first to propose the use of the dialectical dynamic method to analyse culture, which is quite different from the mainstream bipolar paradigm analysis in cross-cultural management. Through a comparative analysis of eight paradoxical values in modern Chinese society, namely "guanxi and professionalism, face and self-expression, thrift and materialism, family orientation and individualism, aversion to and respect for law, hierarchy and competence, long-term and short-term orientation, traditional creeds and modern approaches", Faure and Fang ${ }^{16}$ point out that contemporary Chinese culture has undergone major cultural changes, but in terms of the thinking process, modern Chinese society remains anchored to the classical yinyang approach. Fang ${ }^{9}$ proposed to conceptualize culture as a value orientation with internal contradiction through "situation, context, and time" from the perspective of yinyang. Therefore, there is a paradoxical value in any culture, which is a process of generation, existence, strengthening and complementation, forming the integrity, dynamic, and dialectic of culture. Chen and Miller ${ }^{39}$ emphasized that western management culture should not "lead" but "meet" eastern management culture. They believed that Chinese indigenous organizations must learn from both eastern and western cultures and create better things through the integration of the two. Sometimes it is necessary to integrate opposites, which must also become part of the dual cultural orientation with "social good and self-interest, trust-based and legal relationships, teamwork and individual achievement, risk taking and caution, business and society, locally sensitive and foreign". 39

Pauluzzo et $\mathrm{al}^{40}$ described a cross-case analysis on yinyang balancing ${ }^{17}$ and on the yin-yang philosophy of culture with situation, context, and time ${ }^{9}$ to find that crosscultural learning can help manage cultural dilemmas and lead to greater effectiveness in specific settings. Chen ${ }^{41}$ and $\mathrm{An}$ et $\mathrm{al}^{25}$ proposed from the perspective of organizational communication that the dialectical interaction between yin-yang is the basis of the formation of human communication theory, which provides a new research perspective for cross-cultural communication management. Chen ${ }^{42}$ proposed a communitarianism model based on the dialectics of yin-yang about cultural differences to guide the balance and integration of individualism and collectivism in cross-cultural management. In the latest literature, Chin et $\mathrm{al}^{28}$ propose a new framework for a Confucianism business model based on an integrative view of paradox and culture angle, which is connected to the impact of culture in constructing the frame of business models in the Asia-Pacific area. In that model, social legitimacy, institutional enablers, and institutional disablers were put forward in a yin-yang harmony cognition. ${ }^{28}$ 


\section{Applying the Yin-Yang Perspective to Guide the Practice of Organizational Management}

Applying the yin-yang perspective to guide the analysis of organizational management practice, Li et $\mathrm{al}^{43}$ carried out a case study based on the five characteristics of yin and yang embodied in the management of a Chinese enterprise - "inaction, emptiness, hardness and softness, moderation and harmony" - and proposed that embedding the thought of yin-yang into the enterprise growth model is important for improving the core competitiveness and benefits of enterprises. In China's local management practice, enterprises applying the philosophy of yin-yang will form a "humanized" management paradigm that combines rules with human nature. ${ }^{2,43}$ Jing and Van de ven, ${ }^{35}$ through a case study of an enterprise in China, proposed three key aspects related to the concept of yin-yang and organizational change: situation, process, and action. From the yin-yang perspective, they highlighted the role of "potential" and action strategies and the dialectics of “inaction". Lee and Reade ${ }^{44}$ tested 97 Chinese employees in three Japanese subsidiaries in China to investigate the leadership and followership dynamic in foreign firms in China. They found yin-yang offers an approach to the leadership and cosmopolitan followership which have a positive effect on employee commitment. Chin et $\mathrm{al}^{38}$ put forward an explanation for the cognitive framework of yin-yang, and expounds how to use it as a meta theoretical tool to describe the contradictory and complementary dynamics of Chinese strategic thinking. They proposed eight paradoxical situations facing Chinese organisations based the yin-yang change and raise four strategic propositions regarding how competing Chinese higher education institutes handle the conflicting yet complementary dynamics in China. Horak and Long ${ }^{45}$ analysed the relationship between power and trust in the enterprise organization from the yin-yang perspective, and believed that the relatively natural, mutual integration, and mutual dependence shown by the analysis of yin-yang was more appropriate than that by traditional western management theory in terms of power and trust. Lin et $\mathrm{al}^{7}$ explained the leadership style of Chinese expatriate managers from the perspective of traditional Chinese philosophy. The leadership style of Chinese expatriate managers is influenced by some factors in Chinese traditional philosophy and foreign cultural context, which is consistent with the view of yinyang balance. ${ }^{7}$

\section{Implications of the Study and Directions for Future Research}

The positive growth of China's economy during the period of COVID-19 can be displayed and promoted as a successful development experience in management. Therefore, we believe that the Chinese experience in organizational management can also be concerned and used for reference by non-Chinese audiences. Sorting out the yinyang perspective, a significant characteristic of Chinese management is a contribution to the literature research of management disciplines. We do not emphasize that yinyang is superior than western management theory. We propose that yin-yang perspective can supplement the deficiency of western management theory from dynamic and dialectical aspects. The literature research of management disciplines should not only contain the spirit of western scientific management but also absorb the wisdom of Chinese philosophical management. Chinese indigenous organizations, even some other non-Chinese organizations, can learn from both eastern and western cultures and create better things through the integration of the two. According to the review, applying the yin-yang perspective to the theory of paradox in management is well suited for research on Chinese indigenous characteristics. We examine the paradox in management through the yinyang lens and proposes an application of the yin-yang perspective examined in Chinese indigenous management research. Based on a literature review, the study emphasizes that yin-yang should be part of management theory to guide the practice of organizational management. We believe that our study makes a significant contribution to the literature because it discusses how to improve the practice of organizational management in a cross-cultural background, in the backdrop of an increasing number of Chinese multinationals in world markets and of foreign multinationals in Chinese markets. This study also proposes some directions and implications for future research on the yin-yang perspective by applying it to China's nonprofit organizations, the practice of organizational management in the cross-cultural background, and the awareness of the limitations and deficiencies of the yin-yang perspective.

\section{Theory and Theory Development}

Compared with previous studies, we find that the Chinese concept of yin-yang emphasizes more on the interaction of interdependent contradictions, and further explains the 
dynamic interaction between the two sides of the contradiction, which is not deeply involved in the western management paradox. The traditional Chinese philosophy with yin-yang perspective as the main research perspective can better describe the complex and changeable duality, and better describe the complex dynamics of both sides of the contradiction than the western paradox of management. We think that the traditional Chinese philosophy of yinyang provides a new perspective for the western management paradox, which is the optimization and supplement of the western management paradox. Future research on Chinese indigenous management should be a combination of Chinese and western, and while the essential structure is still the modern western management system, it should be supplemented by and improved upon in terms of effect, purpose, and function through the yin-yang perspective. Whether Chinese culture such as yin-yang philosophy is independent of or complementary to modern western culture will provide ideological and intellectual basis for China's business management.

\section{Applying Yin-Yang Perspective to Non- Profit Organizations in China}

Scholars have proposed traditional theories for non-profit organizations, such as market failure, government failure, and contract failure, using Aristotle's thinking of either/or to assume that non-profits and government are antagonistic. In modern times, many scholars consider that nonprofits and governments can work synergistically, similar to Hegel's both/and dialectics, in ways that meet public needs and benefit both parties. ${ }^{46,47}$ However, the illustration of dualism or exclusive opposites in western literature does not best interpret the relationship between non-profits and the Chinese government. Most existing non-profits in China are directly differentiated from the administrative departments of the government, as a result of the national administrative reform, and takes a "path of generation within the system". ${ }^{48}$ From the perspective of "path dependence", these non-profits are bound to be more or less "official", or strongly or weakly dependent on the government. Based on this, some Chinese scholars state that the unique characteristics of China's non-profits is the "dual nature of government and people", which means that the behaviour of the organization is subject to the dual control of administrative mechanism and autonomous mechanism. $^{49}$
China's non-profits are characterized by the duality of government and people, which makes the relationship between their own development and the government's macro supervision contradictory but often able to effectively deal with the paradox. Therefore, it is important to apply a yin-yang perspective to investigate how and to what extent the relations between the non-profits and the government are based on the former's unique characteristics.

\section{Practice of Organizational Management in the Cross-Cultural Background}

From the literature on yin-yang in organizational management, in addition to Chinese local organizations, applying the yin-yang perspective is especially suitable for crosscultural organizations with Chinese backgrounds. This includes Chinese organizations abroad and foreign organizations in China. On the one hand, Chinese organizations abroad must face contradictions, coordination, and cooperation in leadership and management between the foreign and Chinese cultures. Many of China's overseas organizations also need to consider factors such as the Chinese government's macro supervision. On the other hand, foreign organizations in China are also facing confrontation, cooperation, and adjustment between Chinese cultures and their own. The market-oriented view that western organizations hold needs to consider local policies, regulations, and relations with the government. The underlying logic of value creation in some Chinese business models led by the government may not be dominated by commercial market logic, but by the ultimate vision to fulfil both social and commercial missions. ${ }^{28}$ The yin-yang perspective, which embodies opposition, competition, and pursuit of harmony and balance, can better deal with these complex and dynamic relationships.

\section{Limitation and Deficiency of the Yin-Yang Perspective}

$\mathrm{Li}^{50}$ and $\mathrm{Li}$ et $\mathrm{al}^{29}$ alert indigenous Chinese management researchers to the danger of Chinese exceptionalism and overconfidence in the belief that yin-yang is "superior to all" other cognitive frames or logical systems in dealing with organizational paradoxes. It is also necessary to integrate western management ideas, take their strengths and compensate for their weaknesses, and adopt a way of combining Chinese and western philosophy. ${ }^{1,10,11}$ The traditional thinking of yin-yang has some limitations, 
such as unclear logical analysis and causal relationships, too general and abstract concepts of yin-yang, and lack of operational management practices and tools. ${ }^{18}$ When applying the yin-yang perspective to the analysis of management, we should pay attention not to apply it mechanically and directly, and should not be overconfident that yin-yang is "superior" to all other cognitive frameworks or logical systems in managing paradoxes. ${ }^{29}$ The perspective of yin-yang can supplement the deficiency of western management theory from the dynamic and dialectical aspects, and the formal logic of either/or in the west can also make the indigenous research more rigorous and detailed, strengthen the elaboration of abstract and general logic of yin-yang and causality, reduce the use of local research of traditional Chinese philosophy, and simplify the complexity.

\section{Conclusion}

Through a comparison between Chinese and western dualistic dialectics, the yin-yang perspective seems more suitable for paradox management than the static dialectical logic of either/or and both/and. The yin-yang philosophy treats debates or controversies as dynamic dualities to avoid any one-sided biases. However, the application of traditional Chinese philosophy in the field of management is still in the exploratory stage. Scholars have mainly focused on comparing Chinese and western management theories, involving the yin-yang perspective in the cultural research of organizational management and cross-cultural management. In recent years, some scholars have begun to apply the yin-yang perspective to guide the practice of Chinese indigenous organizational management. However, yin-yang has some limitations, such as unclear logical analysis and causal relationships that cannot be applied independently without the western management system. The yin-yang perspective needs to integrate western culture and management. Therefore, in theory, future research on indigenous organizational management should study how to better integrate Chinese and western management systems, that is, by applying western management systems from the yin-yang perspective. In practice, a comparative analysis from the yin-yang perspective based on the characteristics of Chinese organizations in a cross-cultural background would be useful.

\section{Acknowledgments}

We are grateful for the very helpful and constructive comments and suggestions by the Editors of this journal and two anonymous reviewers. We thank Tony Fang, School of
Business, Stockholm University, Sweden and Guo-Ming Chen, Department of Communication Studies, University of Rhode Island, USA for providing helpful suggestions and comments on earlier versions of this article.

\section{Funding}

This research was funded by the Major Program of National Fund of Philosophy and Social Science of China under Grant no. 16ZDA221 and the Center of Public Diplomacy and Intercultural Communication Research of Guangdong Provincial Humanities and Social Sciences Grant.

\section{Disclosure}

The authors declare no conflict of interest.

\section{References}

1. Cheng C-Y. The 'C' theory: a Chinese philosophical approach to management and decision-making. $J$ Chin Philos. 1992;19 (2):125-153. doi:10.1111/j.1540-6253.1992.tb00115.x

2. Cheng C-Y. The C-theory: on Chinese philosophical approach to decision making, leadership and management. Int J Bus Syst Res. 2010;4(5/6):510-540. doi:10.1504/ijbsr.2010.035073

3. Li PP. Toward an integrative framework of indigenous research: the geocentric implications of Yin-Yang balance. Asia Pac J Manag. 2012;29(4):849-872. doi:10.1007/s10490-011-9250-z

4. Li PP. The unique value of yin-yang balancing: a critical response. Manag Organ Rev. 2014;10(2):321-332. doi:10.1017/ s1740877600004228

5. Xie PH, Wei NJ. Paths exploration for Chinese indigenous management research. Chin J Manag. 2012;9(9):1255-1262.

6. Du R, Ai SZ, Brugha CM. Integrating Taoist Yin-Yang thinking with Western nomology: a moderating model of trust in conflict management. Chin Manag Stud. 2011;5(1):55-67. doi:10.1108/ 17506141111118453

7. Lin L, Li PP, Roelfsema H. The traditional Chinese philosophies in inter-cultural leadership: the case of Chinese expatriate managers in the Dutch context. Cross Cult Strateg Manag. 2018;25(2):299-336. doi:10.1108/CCSM-01-2017-0001

8. Fang T. From 'onion' to 'ocean': paradox and change in national cultures. Int Stud Manag Organ. 2005;35(4):71-90. doi:10.2307/40397646

9. Fang T. Yin Yang: a new perspective on culture. Manag Organ Rev. 2012;8(1):25-50. doi:10.1111/j.1740-8784.2011.00221.x

10. Li PP, Yang ZY. Integration of Chinese and Western philosophies. Chin J Manag. 2017;14(1):26-27.

11. Rowley C, Oh I. Trends in Chinese management and business: change, confucianism, leadership, knowledge \& innovation. Asia Pac Bus Rev. 2020;26(1):1-8. doi:10.1080/13602381.2019.1698707

12. Lu FM, Jing RT, Yin SJ. The dilemma and access of Chinese indigenous management research. Chin J Manag. 2013;10 (12):1717-1724.

13. Cheng C-Y. The C Theory: Chinese Philosophy of Management. Beijing: China Renmin University Press; 2017.

14. Smith WK, Lewis MW. Toward a theory of paradox: a dynamic equilibrium model of organizing. Acad Manag Rev. 2011;36 (2):381-403. doi:10.5465/AMR.2011.59330958

15. Lewis MW. Exploring paradox: toward a more comprehensive guide. Acad Manag Rev. 2000;25(4):760-776. doi:10.5465/ AMR.2000.3707712 
16. Faure GO, Fang T. Changing Chinese values: keeping up with paradoxes. Int Bus Rev. 2008;17(2):194-207. doi:10.1016/j. ibusrev.2008.02.011

17. Li PP. Global implications of the indigenous epistemological system from the East: how to apply Yin-Yang balancing to paradox management. Cross Cult Strateg Manag. 2016;23(1):42-77. doi:10.1108/CCSM-10-2015-0137

18. Su ZX. Management paradox and Yin Yang balancing. Tsinghua Bus Rev. 2017;11:28-36.

19. Smith WK, Erez M, Jarvenpaa S, Lewis MW, Tracey P. Adding complexity to theories of paradox, tensions, and dualities of innovation and change: introduction to organization studies special issue on paradox, tensions, and dualities of innovation and change. Organ Stud. 2017;38(3-4):303-317. doi:10.1177/0170840617693560

20. Ford JD, Backoff RW. Organizational change in and out of dualities and paradox. In: Quinn RE, Cameron KS, editors. Paradox and Transformation: Toward a Theory of Change in Organization and Management. Cambridge, MA: Ballinger; 1988:81-121.

21. March JG. Exploration and exploitation in organizational learning. Organ Sci. 1991;2(1):71-87. doi:10.1287/orsc.2.1.71

22. Xu ZR. Explanation of Zhou Yi Yin Yang. Changchun: Jilin Wenshi Press; 1991.

23. Chen GM. Bian (change): a perceptual discourses of I Ching. Intercult Commun Stud. 2008;17(4):7-17.

24. Fang T, Faure GO. Chinese communication characteristics: a yin-yang perspective. Int $J$ Intercult Relat. 2011;35(3):320-333. doi:10.1016/j.ijintrel.2010.06.005

25. An R, He GH, Chen GM. Intercultural communication influence of confucius institutes: a Yin-Yang perspective. China Media Res. 2018;14(4):37-45.

26. Langevin HM, Badger GJ, Povolny BK, et al. Yin Scores and Yang Scores: a new method for quantitative diagnostic evaluation in traditional Chinese medicine research. J Altern Compl Med. 2004;10 (2):389-395. doi:10.1089/107555304323062392

27. Zhang WR, Zhang L. YinYang bipolar logic and bipolar fuzzy logic. Inf Sci. 2004;165(3-4):265-287. doi:10.1016/j.ins.2003.05.010

28. Chin T, Shi Y, Rowley C, Meng J. Confucian business model canvas in the Asia Pacific: a Yin-Yang harmony cognition to value creation and innovation. Asia Pac Bus Rev. 2020. doi:10.1080/ 13602381.2020.1795481

29. Li X, Worm V, Xie P. Is Yin-Yang superior for paradox research? Cross Cult Strateg Manag. 2018;25(3):501-514. doi:10.1108/CCSM06-2016-0116

30. Redding G. Components and process in social science explanation: is there a role for yin yang balancing? Cross Cult Strateg Manag. 2017;24(1):154-166. doi:10.1108/CCSM-11-2016-0195

31. Luo Y, Zheng Q, Tung R, Ralston D. Competing in complex cross-cultural world. Cross Cult Strateg Manag. 2016;23 (2):386-392. doi:10.1108/CCSM-01-2016-0020

32. Hegel GWF. Logic. Yizhi Y, editor. Beijing: Beijing press; 1982.

33. Chen GM. A Yin-Yang theory of human communication. China Media Res. 2018;14(4):1-15.

34. Bohr N. The quantum postulate and the recent development of atomic theory. Nature. 1928;121(3050):580-590. doi:10.1038/121580a0
35. Jing R, Van de Ven A. A Yin-Yang model of organizational change: the case of CBG. Manag Organ Rev. 2014;10(1):55-80. doi:10.1111/ more. 12045

36. Lin D, Lu J, Li PP, Liu X. Balancing formality and informality in business exchanges as a duality: a comparative case study of returnee and local entrepreneurs in China. Manag Organ Rev. 2015;11 (2):315-342. doi:10.1017/mor.2014.2

37. Li X. Can Yin-Yang guide Chinese indigenous management research? Manag Organ Rev. 2014;10(1):7-27. doi:10.1111/ more. 12042

38. Chin T, Rowley C, Redding G, Wang S. Chinese strategic thinking on competitive conflict: insights from Yin-Yang harmony cognition. Int J Confl Manag. 2018;29(5):683-704. doi:10.1108/IJCMA-092017-0101

39. Chen MJ, Miller D. West meets East: toward an ambicultural approach to management. Acad Manag Perspect. 2010;24(4):17-24. doi:10.5465/amp.2010.24.4.3651479.a

40. Pauluzzo R, Guarda M, Pretto L, Fang T. Managing paradoxes, dilemmas, and change: a case study to apply the Yin Yang wisdom in western organizational settings. Cross Cult Strateg Manag. 2018;25(2):257-275. doi:10.1108/CCSM-08-2017-0094

41. Chen GM. Zhong (centrality), self-competence, and social/communication competence: a Chinese perspective. Intercult Commun Stud. 2016;25(1):17-31.

42. Chen CC. Yin-yang dialectics and communitarianism in cross-cultural management research. Cross Cult Strateg Manag. 2018;25(3):492-500. doi:10.1108/CCSM-11-2016-0199

43. Li J, Wang J, Fan W. Yin yang and company growth: a case study of a coal company of Shanxi in China. Chin Manag Stud. 2011;5 (4):380-393. doi:10.1108/17506141111183154

44. Lee HJ, Reade C. The role of Yin-Yang leadership and cosmopolitan followership in fostering employee commitment in China: a paradox perspective. Cross Cult Strateg Manag. 2018;25(2):276-298. doi:10.1108/CCSM-12-2016-0216

45. Horak S, Long CP. Dissolving the paradox: toward a Yin-Yang perspective on the power and trust antagonism in collaborative business relationships. Supply Chain Manag. 2018;23(6):573-590. doi:10.1108/SCM-01-2018-0013

46. Gidron B, Kramer RM, Salamon LM. Government and the Third Sector: Emerging Relationships in Welfare States. San Francisco: Jossey-Bass; 1992.

47. Salamon LM. Partners in Public Service: Government-Nonprofit Relations in the Modern Welfare State. Baltimore: Johns Hopkins University Press; 1995.

48. Bi JW. The Revolution of Social Groups: An Economic Analysis of the Development of Social Groups in China. Shandong: People's Publishing House; 2003.

49. Wang Y, Zhe XY, Sun BY. Association development and organizational system reconstruction. Manag World. 1992;2:192-202.

50. Li X. The danger of Chinese exceptionalism. Manag Organ Rev. 2016;12(4):815-816. doi:10.1017/mor.2016.41
Psychology Research and Behavior Management is an international peer-reviewed, open access journal focusing on the science of psychology and its application in behavior management to develop improved outcomes in the clinical, educational, sports and business arenas. Specific topics covered in the journal include: Neuroscience, memory and decision making; Behavior modification and management; Clinical applications; Business and sports performance management; Social and developmental studies; Animal studies. The manuscript management system is completely online and includes a very quick and fair peer-review system, which is all easy to use. Visit http://www. dovepress.com/testimonials.php to read real quotes from published authors. 